\title{
Stent-assisted, balloon-induced intimal disruption and relamination of aortic dissection in patients with Marfan syndrome: Midterm outcomes and aortic remodeling
}

\author{
Elsa Madeleine Faure, MD, ${ }^{\text {a,b }}$ Salma El Batti, MD, PhD, ${ }^{a}$ Marwan Abou Rjeili, MD, ${ }^{a}$ \\ Iannis Ben Abdallah, MD, ${ }^{a}$ Pierre Julia, $\mathrm{MD}, \mathrm{PhD},{ }^{\mathrm{a}}$ and Jean-Marc Alsac, $\mathrm{MD}, \mathrm{PhD}^{\mathrm{a}, \mathrm{c}}$
}

\section{ABSTRACT}

Objective: The study objective was to assess the midterm outcomes and aortic remodeling in patients with Marfan syndrome with complicated acute type B aortic dissection treated with stent-assisted, balloon-induced intimal disruption and relamination.

Methods: We reviewed all patients treated with stent-assisted, balloon-induced intimal disruption and relamination for a complicated acute type B aortic dissection associated with Marfan syndrome according to the revised Ghent criteria.

Results: Between 2015 and November 2017, 7 patients with Marfan syndrome underwent stent-assisted, balloon-induced intimal disruption and relamination for a complicated acute type B aortic dissection. The median age of patients was 47 years (range, 23-70). Four patients had a history of aortic root replacement. Technical success was achieved in $100 \%$. Three patients required an adjunctive procedure for renal artery stenting $(\mathrm{n}=2)$ and iliac artery stenting $(\mathrm{n}=1)$. There was no in-hospital death, 30-day postoperative stroke, spinal cord ischemia, ischemic colitis, or renal failure requiring dialysis. At a median follow-up of 15 months (range, 7-28), 1 patient required aortic arch replacement for aneurysmal degeneration associated with a type Ia endoleak at 2 years, giving a late reintervention rate of $14 \%$. There was no other secondary endoleak. The primary visceral patency rate was $100 \%$. There were no all-cause deaths reported. At last computed tomography scan, all patients had complete aortic remodeling of the treated thoracoabdominal aorta. Distally, at the nonstented infrarenal aortoiliac level, 6 patients had persistent false lumen flow with stable aorto-iliac diameter in 5. One patient had iliac diameter growth $(27 \mathrm{~mm}$ diameter at last computed tomography scan).

Conclusions: Stent-assisted, balloon-induced intimal disruption and relamination of aortic dissection in patients with Marfan syndrome is feasible, safe, and associated with an immediate and midterm persisting thoracoabdominal aortic remodeling. (J Thorac Cardiovasc Surg 2018;156:1787-93)

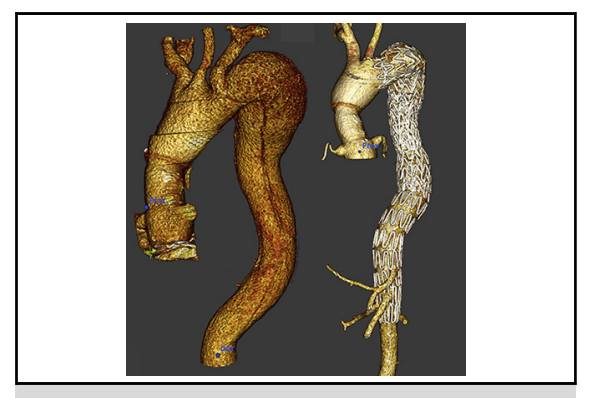

Preoperative and 1-year postoperative CT scans showing remodeling of the thoracoabdominal aorta.

\section{Central Message}

The findings of this study showed that STABILISE in patients with MFS is feasible, safe, and associated with an immediate and midterm persisting thoracoabdominal aortic remodeling.

\section{Perspective}

We report the technique and results in the first 7 patients with MFS and CABAD treated with STABILISE. The study showed that STABILISE improved the aortic prognosis with an immediate and midterm persisting thoracoabdominal aortic remodeling.

See Editorial page 1773.

See Commentary page e303 in the June 2019 issue.
From the ${ }^{\mathrm{a}}$ Department of Vascular Surgery, Hôpital Européen Georges Pompidou, AP-HP, Paris, France; ' $\mathrm{PhyMedExp,} \mathrm{University} \mathrm{of} \mathrm{Montpellier,} \mathrm{INSERM,}$ CNRS, France; and ' INSERM U970, Faculté de Médecine Paris-Descartes, Université Paris 5, Paris, France.

Received for publication Feb 14, 2018; revisions received April 29, 2018; accepted for publication May 7, 2018; available ahead of print June 19, 2018.

Address for reprints: Elsa Madeleine Faure, MD, Service de Chirurgie Vasculaire et Endovasculaire, AP-HP Hôpital européen Georges-Pompidou (Paris), 20-40, rue Leblanc, Paris Cedex 15 75908, France (E-mail: elsafaure@hotmail.com). $0022-5223 / \$ 36.00$

Copyright (c) 2018 by The American Association for Thoracic Surgery https://doi.org/10.1016/j.jtcvs.2018.05.001
Marfan syndrome (MFS) is an inherited connective tissue disorder that affects approximately 1 in 5000 to 1 in 10,000 individuals. ${ }^{1}$ Patients with MFS are prone to develop

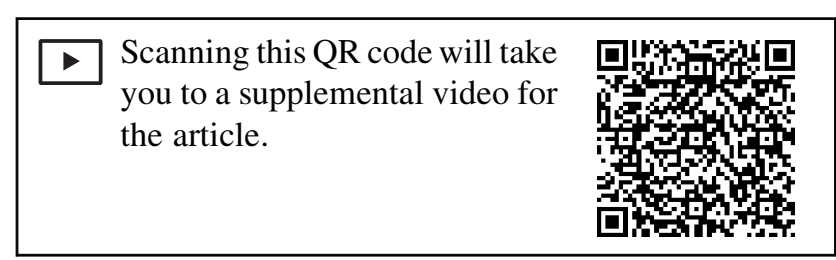




\section{Abbreviations and Acronyms \\ $\mathrm{ABAD}=$ acute type $\mathrm{B}$ aortic dissection \\ $\mathrm{cABAD}=$ complicated acute type $\mathrm{B}$ aortic dissection \\ CT $=$ computed tomography \\ LSA $\quad=$ left subclavian artery \\ MFS $\quad=$ Marfan syndrome \\ STABILISE $=$ stent-assisted, balloon-induced intimal disruption and relamination of aortic dissection
TEVAR $=$ thoracic endovascular aortic repair
ZDES $=$ Zenith Dissection Endovascular Stent

vascular complications, such as aortic dilatation and dissection. Recent research reports that $46.7 \%$ of patients with MFS will develop aortic dissection, ${ }^{2}$ and $1 \%$ of the patients with aortic dissection have connective tissue disorder. ${ }^{3}$ The aortic root is the most frequent part of the aorta involved, before the descending thoracic aorta. Nollen and colleagues ${ }^{4}$ have reported that after aortic root replacement, aortic operations of the descending aorta are required in $50 \%$ of patients over a mean period of 26 years. Improvement of medical and surgical therapy has increased life expectancy in these patients. ${ }^{5,6}$ As a result, the number of patients with MFS requiring interventions of the descending thoracic aorta because of new or residual dissection and dissecting aneurysmal degeneration has substantially increased, all the more so because MFS is a recognized predictor of aortic growth in aortic dissection. ${ }^{7}$ Although conventional surgery for the proximal aorta is well established and associated with good results, open surgery and medical treatment for dissection of the descending thoracic aorta still have disappointing results with up to $20 \%$ morbidity and persistent risk for further reintervention. ${ }^{8}$ Over the past 2 decades, the role of thoracic endovascular aortic repair (TEVAR) has gradually replaced open surgery as the preferred surgical treatment for complicated acute type $\mathrm{B}$ aortic dissection (cABAD) in patients without MFS. ${ }^{9,10}$ However, despite growing evidence about the beneficial role of TEVAR in cABAD since the first experimental reports in $1993,{ }^{11}$ its use for patients with MFS is still under debate. Dong and colleagues ${ }^{12}$ reported a lower rate of aortic remodeling in patients with MFS because of the occurrence of stent graft-induced new entry reported in 33\% of patients with MFS and only 3\% in patients without MFS, with an increasing rate of persistent false lumen flow and late aortic dilatation. These findings prompted us to propose the stent-assisted, balloon-induced intimal disruption and relamination of aortic dissection (STABILISE) technique in patients with MFS with complicated acute type $\mathrm{B}$ dissection to achieve extensive aortic remodeling and prevent late aneurysm evolution. The technique, first reported in 2014, ${ }^{13}$ was never reported in patients with MFS, although they are likely to be those who may benefit the most. The aim of this study was to assess the procedural feasibility and early and midterm outcomes of the STABILISE technique in patients with MFS with cABAD.

\section{PATIENTS AND METHODS}

The Georges Pompidou European Hospital Ethics Committee approved this retrospective study and waived the need for individual patient consent (CERHUPO 2015-10-03). All patients gave informed consent to each procedure.

\section{Patients}

From November 2011 to November 2017, TEVAR was performed in all patients who presented to our tertiary referral center with acute type B aortic dissection (ABAD) if complicated according to the 2017 European Society for Vascular Surgery Guidelines on the Diagnosis and Management of Descending Aorta Diseases ${ }^{14}$ or associated with poor prognostic factors involving maximum aortic diameter of the dissected aorta greater than $40 \mathrm{~mm}$. The STABILISE technique was performed concomitant with proximal entry tear stent grafting in cases of extension of dissection to the level of the abdominal aorta and residual flow in the false lumen of the abdominal aorta distally to the stent graft on preoperative angiography or in a second-stage procedure in cases of secondary false lumen reperfusion distal to proximal stent graft on postoperative control computed tomography (CT) scan.

We performed a retrospective review of a prospective maintained database of acute aortic dissections performed in our department to identify patients with MFS who received STABILISE for a cABAD. Patients with MFS were considered if the diagnosis was established before STABILISE procedures according to the revised Ghent criteria. ${ }^{15,16}$ Patients without MFS who received STABILISE for a cABAD were excluded from the study.

Medical records were analyzed for preoperative patient characteristics, dissection morphology, details of operative strategy, intraoperative events, and postoperative course. Indication for STABILISE was retained in those with MFS presenting with an ABAD if complicated (malperfusion or rupture) or associated with poor prognostic factors involving proximal false lumen rapid expansion during initial hospitalization at the reevaluation CT, maximum aortic diameter of the dissected aorta greater than $40 \mathrm{~mm}$, refractory pain, or refractory hypertension despite optimal medical treatment.

The STABILISE technique was performed concomitant with conventional stent graft coverage of the primary entry tear in case of persistent false lumen patency distal to the stent graft assessed at preoperative completion angiogram or in a second-stage procedure in case of distal false lumen reperfusion or extension of the dissection at postoperative CT.

\section{Preoperative Management}

Baseline CT with multiplanar reconstruction (Figures 1, A-D , and 2, A) was performed in all patients to assess the dissection characteristics, such as location of the primary entry tear, extension of the dissection, and patency and origin (true or false lumen) of visceral vessels; to choose the peripheral access site; and to perform stent-graft sizing.

\section{Proximal Stent-Graft}

The operative technique did not differ from that used in patients without MSF. The aim of the proximal stent-grafting was both to close the primary entry tear to obtain proximal sealing and to exclude the dilated proximal half of the descending thoracic aorta. In our experience, using a Conformable Gore TAG stent graft (C-TAG, WL Gore \& Associates, Inc, Flagstaff, 


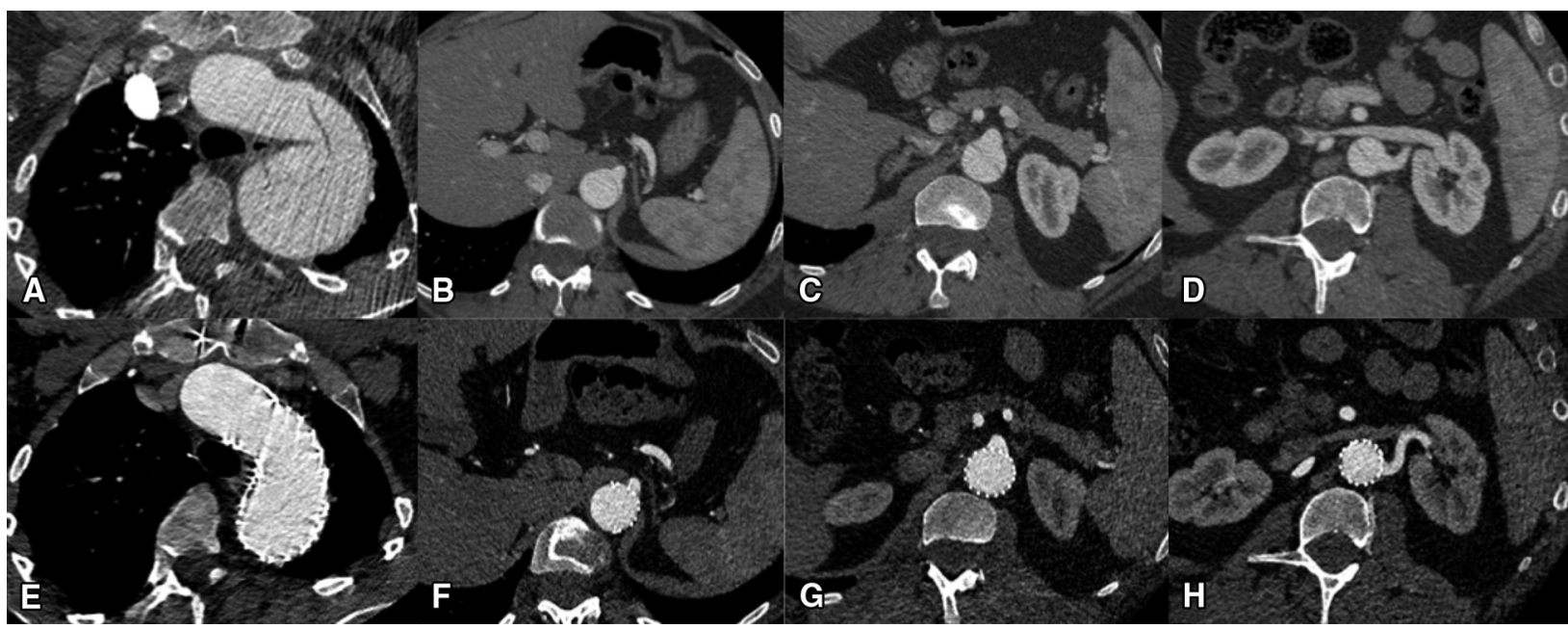

FIGURE 1. Preoperative (A-D) and 1-year follow-up after STABILISE (E-H). CT of a patient with MFS treated for cABAD. A, E, Aortic arch level. B, F, Coeliac trunk level. C, G, Superior mesenteric artery level. D, H, Left renal artery level.

Ariz) offers the comfort of a single sheath procedure through a single femoral access. The diameter of the stent graft was sized on the basis of its proximal sealing zone in the arch with an oversizing of maximum $10 \%$ in native aorta, but also to obtain a distal sealing on both the true and the false lumens at the level of the descending thoracic aorta. Because "off-the-shelf" stent-grafts allow sealing on a maximum aortic diameter of $42 \mathrm{~mm}$ with their larger designs $(45-46 \mathrm{~mm})$, the distal part of the stent graft should land in an area where the global diameter of the aorta does not exceed $42 \mathrm{~mm}$ on at least a 20 -mm length. Therefore, the length of the stent graft was adapted to fulfill this condition. If no adequate distal landing zone $42 \mathrm{~mm}$ or less can be reached above the coeliac trunk, the STABILISE technique should not be recommended.

\section{Stent-Graft Implantation}

All procedures were performed in a hybrid-operating suite with the patients under general anesthesia. The femoral artery side of insertion depended on the extension of the dissection within the aortic bifurcation and iliac arteries, and the side with the easier access to the true lumen was chosen. After puncture of the common femoral artery, an angiogram at the visceral level through a $5 \mathrm{~F} 120-\mathrm{cm}$ pigtail catheter was initially performed to confirm its correct position in the true lumen. The pigtail could then be advanced to the ascending aorta, and a Lunderquist Extra Stiff Double Curved Exchange Guide Wire (Cook Medical, Bloomington, Ind) was placed over the pigtail catheter up to the aortic valve. A 24F Dryseal sheath was placed through the femoral access, and a C-TAG stent graft was then advanced and deployed as usual on the landmark of an aortic arch angiogram to ensure proximal sealing. The left subclavian artery (LSA) was covered if necessary to enable proximal entry tear closure after adequate collateral cerebral circulation had been confirmed. LSA revascularization should be performed when recommended.

\section{Distal Aortic Bare Stent Deployment}

The bare stent component is constructed of stacked Z-stents joined by polypropylene sutures, which can be deployed through a $16 \mathrm{~F}$ sheath. An angiogram at the level of the thoracoabdominal aorta, comprising the distal part of the stent graft, all arising visceral arteries, and the distal marker of the $24 \mathrm{~F}$ sheath in the infrarenal aorta, was performed to serve as a roadmap. The delivery system of the Zenith Dissection Endovascular Stent (ZDES) (Cook Medical, Bloomington, Ind) was then exchanged and advanced through the $24 \mathrm{~F}$ sheath on the true lumen extrastiff wire. Its optimal deployment should be aiming for a 1-stent body overlap in the proximal stent graft and an extension to the level of the infrarenal aorta. The ZDES 36-mm diameter was chosen for a maximum external aortic diameter up to $32 \mathrm{~mm}$, and the ZDES 46-mm diameter was chosen for a maximum external aortic diameter between 32 and $42 \mathrm{~mm}$. The extent of aortic delamination determined the choice of ZDES length. However, the infrarenal aorta was never entirely stented. When the dissection involved the iliac arteries, the bare stent was extended 2 to $4 \mathrm{~cm}$ below the renal arteries to prevent iliac artery flow when supplied by the false lumen. Angiography of the visceral aorta confirmed an incomplete expansion of the true lumen with residual and retrograde flow in the false lumen.

\section{Management of the Visceral Arteries Supplied by the False Lumen}

In cases of visceral or renal branches arising from the false lumen or presenting signs of static malperfusion on preoperative $\mathrm{CT}$, we recommend catheterizing the targeted vessels through the struts of the aortic bare stent before its balloon expansion. This catheterization with a $6 \mathrm{~F} 65-\mathrm{cm}$ long sheath, supported on a Rosen 0.035-inch wire $(180 \mathrm{~cm}$ ) (Boston Scientific, Natick, Mass), will allow guidance of the intimal ostium during relamination of the flap to realign it on the targeted vessel origin. The $6 \mathrm{~F}$ long sheath was placed through the same 24F Dryseal Sheath, parallel to the initial aortic Lunderquist. This maneuver also allows access to the vessel for potential stenting after aortic bare stent dilatation.

\section{Balloon Dilatation of the Bare-Stent}

Subsequently, a tri-lobe balloon catheter (Gore Medical Inc; large size for 26-42 mm aortic diameter) was inserted via the $24 \mathrm{~F}$ sheath on the Lunderquist extra stiff wire, parallel to the potential $6 \mathrm{~F}$ sheath(s) of collateral vessel(s). After accurate positioning at the level of the overlap zone between the distal end of the stent graft and the proximal end of ZDES, the balloon was manually inflated under fluoroscopic guidance using an endoflater device to measure balloon pressure to ensure that the pressure does not exceed $4 \mathrm{~atm}$, which was the pressure reported by Hofferberth and colleagues. ${ }^{13}$ Balloon expansion in the stent graft was undertaken to the point of intimal flap disruption, leading to reapposition of the intimal flap to the aortic wall. Self-expansion of the aortic bare stent secures complete relamination of aortic wall. Serial balloon dilatation of the stented true lumen was undertaken in the caudal direction to propagate the intimal flap disruption and simultaneously relaminate the intima to the aortic wall, all the way down to the infrarenal aorta (Video 1). Balloon pressures ranged from 1 to 2 atm with manual inflation to approximately $90 \%$ of total aortic size 


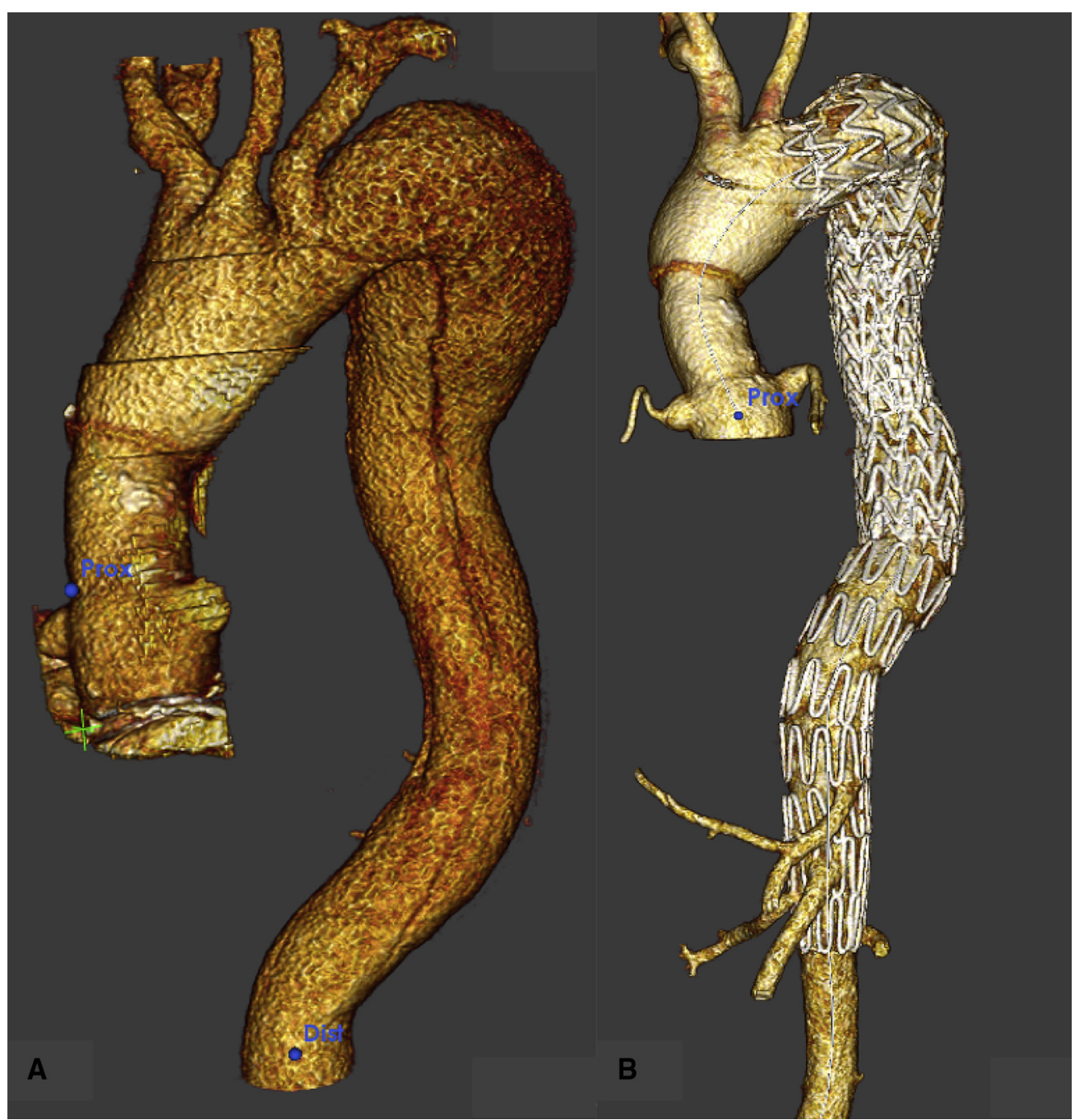

FIGURE 2. Preoperative (A) and 1-year postoperative (B) CT scans showing remodeling of the thoracoabdominal aorta.

to enable intimal disruption without applying this pressure to the outer aortic wall. On completion of balloon angioplasty, an angiogram was performed to ensure adequate proximal and distal seal of the false lumen to assess false lumen obliteration and branch vessel patency in the thoracoabdominal aorta. In cases of visceral or renal artery malperfusion, a nitinol or balloon-expandable bare stent can be advanced on the Rosen guidewire, protected in the $6 \mathrm{~F}$ long sheath, and deployed with an approximately 3-mm protrusion beyond the bare stent mesh into the aortic true lumen.

\section{RESULTS}

\section{Baseline Characteristics}

From November 2015 to November 2017, 7 patients with MFS underwent the STABILISE procedure for cABAD. During this period, no other patients with MFS were treated for a complicated acute type B dissection at our institution. Two patients presented with malperfusion syndrome, and 5 patients presented with maximal aortic diameter greater than $40 \mathrm{~mm}$ and rapid aortic growth at controlled CT during initial hospitalization.
Six patients were male, and the median age was 47 years (range, 23-70). Four patients had a history of aortic root replacement. Preoperative patient demographics, anatomic dissection characteristics, and selection for STABILISE are detailed in Table 1.

\section{Procedural Outcomes}

The median interval from dissection diagnosis to STABILISE procedure was 3 days (range, 1-11 days). STABILISE was performed concomitant with TEVAR in 5 patients and in a second-stage procedure because of dissection evolution distal to the stent graft on postTEVAR CT scan in 2 patients with a delay of 2 and 11 days, respectively.

Proximal anchoring to close the primary entry tear and to obtain proximal sealing was in zone 3 in 5 patients and in zone 2 in 2 patients with LSA coverage without revascularization. Median proximal stent graft diameter was $40 \mathrm{~mm}$ 


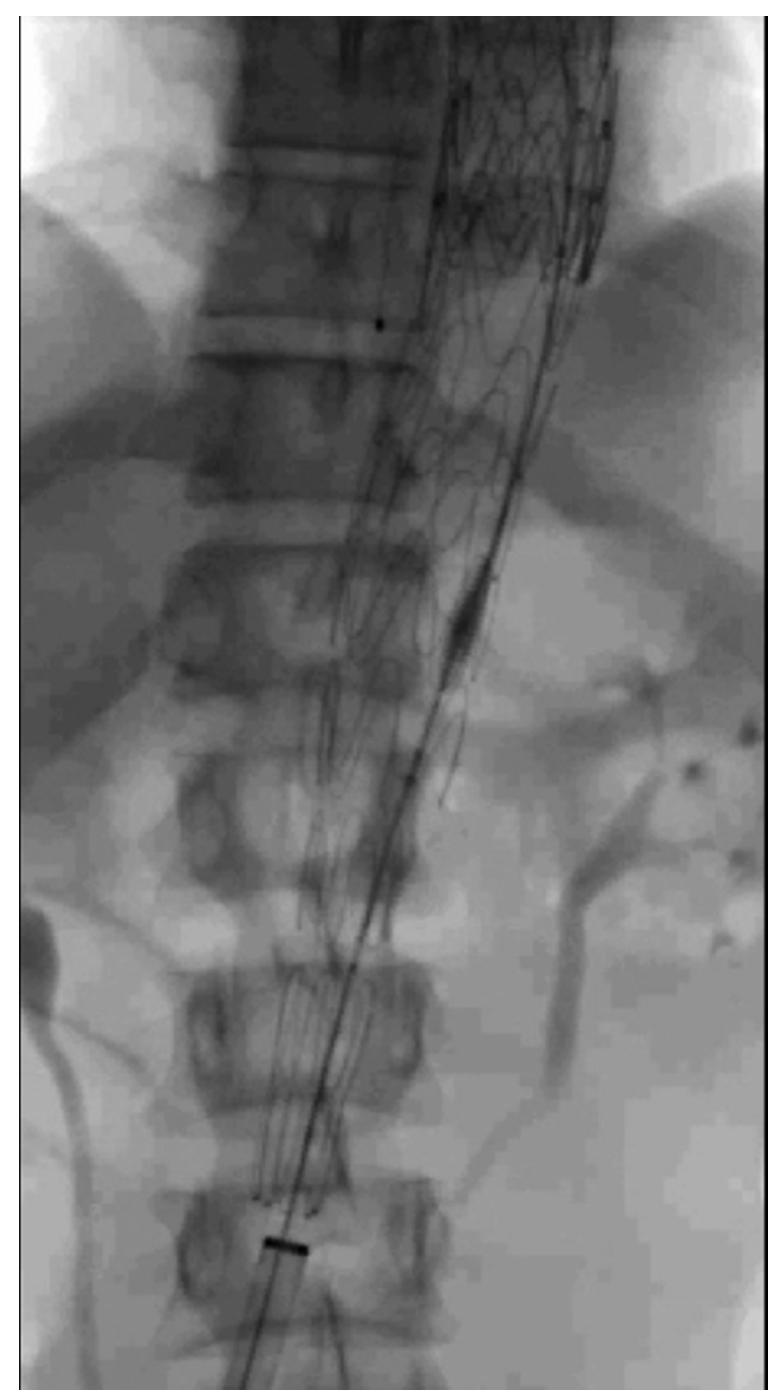

VIDEO 1. Serial balloon dilatation of the stented true lumen in the caudal direction to propagate the intimal flap disruption and simultaneously relaminate the intima to the aortic wall. Video available at: https://www.jtcvs.org/ article/S0022-5223(18)31259-5/fulltext.

(range, 37-45 mm). Median proximal oversizing of the stent graft was $10 \%$ (range, $10 \%-15 \%$ ).

The median length of stent graft aortic coverage was $200 \mathrm{~mm}$ (range, 200-250 mm). The distal end of the stent graft was located at the level of $\mathrm{T} 7$ in 1 patient and between T8 and T10 in 6 patients. Median aortic diameter at the distal landing zone was $34 \mathrm{~mm}$ (range, 31-38 $\mathrm{mm}$ ). Distal to the stent graft, all patients received only 1 bare stent. The type of bare stent used was a ZDES 46-185 in 4 patients and a ZDES 46-164 in 3 patients. The distal end of the bare stent was in the infrarenal aorta in all patients, 3 to $4 \mathrm{~cm}$ below the renal arteries. Three patients required a concomitant procedure for left renal artery stenting $(\mathrm{n}=1)$, right renal artery stenting $(\mathrm{n}=1)$, and iliac artery stenting $(\mathrm{n}=1)$.

All stented arteries were dissected or supplied by the false lumen at preoperative CT. No intraprocedural
TABLE 1. Baseline characteristics

\begin{tabular}{ll}
\hline \multicolumn{1}{c}{ Variable } & N (\%) \\
\hline Age, y & 47 \\
Female & $1(14)$ \\
Hypertension & $1(14)$ \\
Prior aortic surgery* & $4(57)$ \\
Anatomic dissection characteristics & \\
$\quad$ Infrarenal extension of the dissection & $1(14)$ \\
$\quad$ Iliac extension of the dissection & $6(86)$ \\
$\quad$ Visceral arteries supplied by false lumen & $5(18)$ \\
Indication for STABILISE & \\
$\quad$ Malperfusion & $2(29)$ \\
$\quad$ False lumen aortic growth $>5$ mm and Maximum & $5(71)$ \\
$\quad$ aortic diameter $>40$ mm $\dagger$ & \\
\hline
\end{tabular}

STABILISE, Stent-assisted, balloon-induced intimal disruption and relamination of aortic dissection. *Aortic root and ascending aorta prosthetic replacement up to the brachiocephalic trunk. † $\dagger$ During initial hospitalization.

complication occurred in relation to endovascular device deployment or intimal flap disruption. At completion angiogram, all patients had the false lumen completely excluded at the stent graft and bare stented levels (from the arch to infrarenal aorta). No endoleak was detected, and there were no aortic or branch vessel injuries.

\section{Early Outcomes ( $<30$ Days)}

There was no postoperative death, stroke, spinal cord ischemia, ischemic colitis, or renal failure requiring dialysis. One patient had prosthetic replacement of the ascending aorta at 5 days after STABILISE for a preexisting aneurysm of $62 \mathrm{~mm}$ of diameter diagnosed at preoperative CT.

\section{Midterm Outcomes ( $>30$ Days)}

The median length of follow-up was 15 months (range, 7-28). One patient developed a chronic aneurysmal degeneration of the aortic arch without associated type A dissection. During the patient's follow-up for aortic arch dilatation, he developed a secondary type Ia endoleak and required aortic arch replacement to treat the aneurysmal degeneration and type Ia endoleak 2 years after STABILISE intervention, giving a late reintervention rate of $14 \%$. Primary visceral patency rate was $100 \%$. There were no allcause deaths reported.

\section{Aortic Remodeling}

At the last CT, all patients showed complete aortic remodeling at the stent-graft level (Figure 1,E) and at the bare-stent level (Figures 1, F-H, and 2, B), without aortic enlargement, giving a positive remodeling rate of $100 \%$ up to the infrarenal level. Distally, at the unstented infrarenal aortoiliac level, only 1 patient had complete aortic remodeling. The other 6 patients had persistent false lumen 
flow, with stable aortoiliac diameter in 5. Only 1 patient developed an iliac aneurysm measuring $27 \mathrm{~mm}$ at the last CT. All 7 patients are still under surveillance, and no aortic reintervention has been required so far.

\section{DISCUSSION}

We reported the midterm results of the first case series of patients with MFS treated for cABAD using the already described STABILISE technique. ${ }^{13}$ In this study, the STABILISE technique led to an immediate and extensive remodeling of the thoracoabdominal aorta with intimal flap delamination, which eliminated the risk for persistent false lumen flow in the most critical part of the aorta: the thoracic descending and visceral part. We reported positive remodeling at an extended thoracoabdominal level in all patients, and the rate of secondary endoleak and reintervention was $14 \%$. Comparatively, after TEVAR alone for ABAD in patients with MFS, Eid-Lidt and colleagues ${ }^{17}$ reported a $44.4 \%$ rate of secondary endoleak with $33.3 \%$ of late reinterventions and positive remodeling documented in only $37.5 \%$. At the infrarenal unstented level, despite persistent false lumen flow in 6 patients $(86 \%)$, the aorto-iliac diameter remained stable in 5 of 6 patients in our study. It is likely that patients will have more infrarenal aorto-iliac enlargement with longer follow-up; however, the infrarenal aorta would be easier to treat later, with a low operative risk, in case of aneurysmal evolution in this area.

Another issue with TEVAR in patients with MFS concerned the proximal anchoring zone in this population with an aortic wall weakened by the disease. It was obvious that in patients with MFS, the aortic arch diameter would show a tendency to increase and to compromise proximal sealing when the proximal anchoring of the stent graft was in the native thoracic aorta, which occurred in 1 of the patients in this study. In 2005, Milewicz and associates ${ }^{5}$ suggested that stent grafts should not be used in the abdominal or thoracic aorta in patients with MFS or other connective tissue disease, except if the stent graft proximal neck was deployed into a graft. However, since 2005, the thoracic stent graft has largely evolved to obtain more compliance and conformability, and this statement should be reconsidered. In this study, the proximal anchoring of the stent graft was in the native aorta in all cases, and we reported $1 \mathrm{sec}-$ ondary type I proximal endoleak (14\%) at 2 years after STABILISE intervention due to aneurysmal degeneration of the aortic arch. This rate of proximal type I endoleak, similar to the $12.5 \%$ of secondary type I endoleak reported by Botta and colleagues, ${ }^{18}$ when proximal anchoring was in the native aorta of patients with MFS was not higher when compared with the $17 \%$ to $21 \%$ rate of type Ia endoleak frequently reported in the literature after TEVAR for type B dissection in patients without MFS. ${ }^{19,20}$ If long-term proximal sealing is still an issue in patients with MFS, we assume that it should not be a contraindication for TEVAR in the setting of acute thoracic aortic syndrome. However, patients with MFS required even more frequent follow-up with CT to make an early diagnosis of aortic enlargement or type I endoleak and propose prompt treatment.

Another discussion was the risk of retrograde type A dissection in MFS, especially in the setting of acute dissection. ${ }^{21}$ However, most patients with MFS presenting with ABAD had previous open surgical replacement of the aortic root, which is the part of the aorta that is affected earlier, or they would soon be treated. In a recent review of TEVAR in patients with MFS, $81 \%$ of the patients treated for the descending thoracic aorta had previous aortic root replacement, ${ }^{22}$ and in our study this applies to more than half of the patients.

Another important point to highlight is that we did not report aortic rupture during balloon inflation in patients with MFS, and balloon pressures do not vary in those without MFS (range, 1-2 atm) to enable intimal disruption, which means that despite the weakness of the aortic wall in patients with MFS, the technique does not compromise its integrity.

\section{Study Limitations}

This is a small cohort of patients with midterm follow-up. The STABILISE technique should be assessed in a larger cohort of patients with MFS and with longer follow-up to draw general conclusions.

\section{CONCLUSIONS}

Our results suggest that the STABILISE technique in cABAD is feasible and safe in patients with MFS. In this study, it was associated with an immediate and midterm persisting remodeling of the thoracoabdominal aorta, which should improve long-term outcomes for this group of patients with a particularly high-risk of complications. Longer follow-up in larger studies is needed to better determine the beneficial role of STABILISE for these patients.

\section{Conflict of Interest Statement}

Authors have nothing to disclose with regard to commercial support.

\section{References}

1. Pieritz RE. The Marfan syndrome. Annu Rev Med. 2000;51:481-510.

2. Groth KA, Stochholm K, Hove H, Kyhl K, Gregersen PA, Vejlstrup N, et al. Aortic events in a nationwide Marfan syndrome cohort. Clin Res Cardiol. 2017;106:105-12.

3. McClure RS, Brogly SB, Lajkosz K, Payne D, Hall SF, Johnson AP. Epidemiology and management of thoracic aortic dissections and thoracic aortic aneurysms in Ontario, Canada: a population-based study. J Thorac Cardiovasc Surg. 2018;155:2254-65.

4. Nollen GJ, Groenink M, Tijssen JG, Van Der Wall EE, Mulder BJ. Aortic stiffness and diameter predict progressive aortic dilatation in patients with Marfan syndrome. Eur Heart J. 2004;25:1146-52.

5. Milewicz DM, Dietz HC, Miller DC. Treatment of aortic disease in patients with Marfan syndrome. Circulation. 2005;111:e150-7. 
6. Finkbohner R, Johnston D, Crawford ES, Coselli J, Milewicz DM. Marfan syndrome: long-term survival and complications after aortic aneurysm repair. Circulation. 1995;91:728-33

7. Van Bogerijen GH, Tolenaar JL, Rampoldi V, Moll FL, Van Hervaarden JA, Jonker FH, et al. Predictors of aortic growth in uncomplicated type B aortic dissection. J Vasc Surg. 2014:59:1134-43.

8. Girdauskas E, Kuntze T, Borger MA, Falk V, Mohr FW. Distal aortic reinterventions after root surgery in Marfan patients. Ann Thorac Surg. 2008; 86:1815-9.

9. Nienaber CA, Kische S, Rousseau H, Eggebrecht H, Rehders TC, Kundt G, et al. Endovascular repair of type $\mathrm{B}$ aortic dissection: long-term results of the randomized investigation of stent grafts in aortic dissection trial. Circ Cardiovasc Interv. 2013;6:407-16

10. Nauta FJ, Trimarchi S, Kamman AV, Moll FL, Van Herwaarden JA, Patel HJ, et al. Update in the management of type B aortic dissection. Vasc Med. 2016; 21:251-63.

11. Moon MR, Dake MD, Pelc LR, Liddell R, Castro LJ, Mitchell RS. Intravascular stenting of acute experimental type B dissections. J Surg Res. 1993;54:381-8.

12. Dong Z, Fu W, Wang Y, Wang C, Yan Z, Guo D, et al. Stent graft-induced new entry after endovascular repair for Stanford type B dissection. J Vasc Surg. 2010; $52: 1450-7$.

13. Hofferberth SC, Nixon IK, Boston RC, McLachlan CS, Mossop PJ. Stent-assisted balloon-induced intimal disruption and relamination in aortic dissection repair: the STABILISE concept. J Thorac Cardiovasc Surg. 2014;147:1240-5.

14. Riambau V, Böckler D, Brunkwall J, Cao P, Chiesa R, Coppi G, et al. Editor's choice - management of descending thoracic aorta diseases clinical practice guidelines of the European Society for Vascular Surgery (ESVS). Eur J Vasc Endovasc Surg. 2017:53:4e52.
15. Dean J. Marfan syndrome: clinical diagnosis and management. Eur J Hum Genet 2007; 15:724-33

16. Loeys BL, Dietz HC, Braverman AC, Callewaert BL, De Backer J, Devereux RB et al. The revised Ghent nosology for the Marfan syndrome. J Med Genet. 2010; 47:476-85.

17. Eid-Lidt G, Gaspar J, Melendez-Ramirez G, Cervantes SJ, Gonzalez-Pacheco H, Damas de los Santos F, et al. Endovascular treatment of type B aortic dissection in patients with Marfan syndrome: mid-term outcomes and aortic remodeling. Catheter Cardiovasc Interv. 2013;82:E898-905.

18. Botta L, Russo V, La Palombara C, Rosati M, Di Bartolomeo R, Fattori R. Stent graf repair of descending aortic dissection in patients with Marfan syndrome: an effective alternative to open reoperation? J Thorac Cardiovasc Surg. 2009;138:1108-14.

19. Faure EM, Canaud L, Agostini C, Shaub R, Boge G, Marty-Ane C, et al. Rein tervention after thoracic endovascular aortic repair of complicated aortic dissection. J Vasc Surg. 2014;59:327-33.

20. Liu Z, Zhang Y, Lui C, Huang D, Zhang M, Ran F, et al. Treatment of serious complications following endovascular aortic repair for type B thoracic aortic dissection. J Int Med Res. 2017;45:1574-84.

21. Gandet T, Canaud L, Ozdemir BA, Ziza V, Demaria R, Albat B, et al. Factors favoring retrograde aortic dissection after endovascular aortic arch repair. J Thorac Cardiovasc Surg. 2015;150:136-42.

22. Parisi R, Secco GG, Di Eusanio M, Fattori R. Endovascular repair of aortic dissection in Marfan syndrome: current status and future perspectives. Diseases. 2015:3:159-66.

Key Words: Marfan, dissection, aorta, TEVAR, bare-stent, STABILISE 